\title{
Cultivating ecological imagination with a web-based mythology
}

\author{
Stephanie Varga \\ University of Alberta
}

\section{Key Highlights:}

- A framework for building a web-based game about climate change

- The paper presents suggestions for acclimatizing teachers to a new way of developing lessons

- Direction for future study includes an arts-based research study integrated into a workshop for teachers

\section{Abstract}

This generative, theoretical descriptive paper, presents a framework I have designed to help teachers create on-line lessons that weave science from the curriculum into mythology. By mythologizing the curriculum, the teacher broadens the mindset of their students by allowing them to see the living-Earth as interconnected. This framework is timely, as many students are reacting to the policy around climate change, or absence of it, with fear and anxiety. The culminating artistic project of the digital game provides an opportunity for expression. It calls on the player to create a work of art that connects what they have learned from the game with their own experiences. The artistic project values the perspective of each contributor so that their anxieties can be heard. A direction for future research is a study that is embedded in a workshop for teachers. The workshop gives teachers an opportunity to learn about the framework while the study aims to learn about the myth-building experiences of teachers. The study follows the arts-based-research paradigm so that primacy can be given to the myths created by the teachers. As an exemplar of this framework, I present an online game I have created that connects several domains pertinent to the education of climate change including the personal, the social, and the scientific. The Google Sites game includes an assessment with instructions.

Keywords: Mythology, Arts Based Research, Curriculum, Science Education, Climate Change, Freshwater and Saltwater, Alberta Grade Eight, Serious Game, Gamification

Cite as: Varga S. 2021. title. Alberta Academic Review, Vol 4 (1): 6, EEGSA-SEGSA Special Issue: Remote Connections, DOI: 10.29173/aar126 